\title{
Hospitalization Expenses and Influencing Factors for Inpatients with Ischemic Heart Disease in Iran: A Retrospective Study
}

\author{
Maryam Shirvani Shiri $\mathbb{D}^{1}{ }^{1}$, Sara Emamgholipour ${ }^{1}{ }^{1,}{ }^{*}$, Rajabali Daroudi ${ }^{2}$, Maryam Tatary ${ }^{3}$, Zohreh \\ Kazemi ${ }^{1}$ and Hassan Karami ${ }^{4}$ \\ ${ }^{1}$ Department of Health Management and Economics, School of Public Health, Tehran University of Medical Sciences, Tehran, Iran \\ ${ }^{2}$ National Center for Health Insurance Organization, Department of Health Management and Economics, School of Public Health, Tehran University of Medical Sciences, \\ Tehran, Iran \\ ${ }^{3}$ Department of Epidemiology and Biostatistics, School of Public Health, Tehran University of Medical Sciences, Tehran, Iran \\ ${ }^{4}$ Department of Health Economics, School of Health Management and Information Sciences, Iran University of Medical Sciences, Tehran, Iran \\ "Corresponding author: Department of Health Management and Economics, School of Public Health, Tehran University of Medical Sciences, Tehran, Iran. Email: \\ s-emamgholipour@tums.ac.ir
}

Received 2021 July 09; Revised 2021 December 03; Accepted 2021 December 06.

\begin{abstract}
Background: Ischemic heart disease (IHD) is the leading cause of death and disability worldwide and in Iran, which imposes a heavy financial burden both on patient's family and society.

Objectives: This study aimed to analyze the direct medical costs of inpatients with IHD and its influencing factors in Iran in 2020. Methods: The sample of this cross-sectional study included 41,357 patients with IHD selected from the hospital information system (HIS) of the Iran Health Insurance Organization from August 23, 2019, to June 20, 2020. The study used the claims data of these patients, which included their demographics, length of stay (LOS), intensive care unit (ICU) admission, hospital accreditation grade, hospital ownership type, and patient discharge status. The multiple linear regression model was employed to evaluate the relationship between hospitalization costs and the associated factors. All statistical tests were conducted at the significance level of $\mathrm{P}<0.05$ using the R 3.6.3 software.

Results: The mean age of patients was $63.95 \pm 12.63$ years old, and most of them were male (54.4\%). The mean hospitalization cost per patient and per day was $586.42 \pm 472.51$ USD and 103.64 \pm 100.29 USD, respectively. Moreover, the mean LOS was 4.92 days. Drugs and consumable medical supplies, as well as nursing and hoteling services, had the highest shares of hospitalization costs (29.54\% and $29.4 \%$, respectively). The hospitalization costs of patients with IHD were higher among men $(\beta=1.24)$, age $61-70$ years $(\beta=1.38)$, $\operatorname{LOS} \geq 5(\beta=2.92)$, ICU admission $(\beta=1.62)$, Iranian health fund $(\beta=1.21)$, and private hospitals $(\beta=1.91)$. Top-grade and first-grade hospitals had higher costs compared to grade $2(\beta=0.67)$, grade $3(\beta=0.35)$, and grade $4(\beta=0.72)$ hospitals. Deceased patients had also higher costs than patients with complete recovery $(\beta=0.63)$, relative recovery $(\beta=0.59)$, follow-up $(\beta=0.51)$, transfer to other medical centers $(\beta=0.44)$, and discharge against medical advice (DAMA) $(\beta=0.62)$.

Conclusions: According to the results, shortening the LOS and controlling the high costs of drugs and consumable medical supplies are among the main strategies to reduce high hospitalization costs.
\end{abstract}

Keywords: Hospitalization Costs, Influencing Factors, Ischemic Heart Disease, Iran

\section{Background}

Cardiovascular diseases (CVDs) are considered the principal cause of early death in the world (1). Among CVDs, ischemic heart disease (IHD) is the most common one (2). IHD is a condition in which the myocardium receives inadequate oxygen as the result of an imbalance between myocardial oxygen supply and demand (3). Depending on the severity of stenosis in arteries and myocardial responses, angina pectoris (chest pain), sudden cardiac death, acute myocardial infarction (AMI), and chronic IHD are manifested (4). The global prevalence and mortal- ity rate of IHD in 2017 was 126.5 million and 8.9 million individuals, respectively, which showed an increase of $74.5 \%$ and $52.3 \%$, respectively, compared to 1990 . Moreover, it was responsible for 15.3 million disability-adjusted life years (DALY) and 165 million years of life lost (YLL) in 2017 (5).

Although the mortality rates of CVDs have declined in the last decades in developed countries (2), the mortality rates and global burden caused by IHD have an upward trend in developing and newly developed countries, especially in the Eastern Mediterranean Region (EMR) (6), which has the highest prevalence of CVDs (7). 
IHD was considered the first cause of mortality in Iran in 2019 (1). The age-standardized prevalence and mortality rate of IHD in Iran was 5143.08 per 100,000 people and 121.95 per 100,000 people in 2019 , respectively (8). The impacts of IHD are not only limited to death and disability, but they also include critical health and economic outcomes (9). All countries are concerned mainly about the resulting costs of IHD. Among the different expenses of IHD, inpatient care accounted for more than half of the costs, followed by pharmaceutical treatment expenditure (10-14). In a study conducted by Schlatter et al. in Brazil, the average outpatient costs of IHD were 1521 USD, while its average inpatient costs were reported as 1976 USD in 2017 (15). In France, the direct medical costs of coronary artery disease (CAD) were estimated at 4183 million Euros, 50\% of which came from inpatient care (16). A study by Darba et al. also revealed the inpatient costs of CAD at 1491.18 PPP \$ (17), imposing costs equivalent to $0.5 \%$ of gross domestic product (GDP) in Iran in 2016 (17); these costs were estimated at $0.32 \%$ of GDP in Korea (18) and 3.37\% of GDP in the United States (19).

Given the high burden of IHD and enormous financial costs on the health system and society, a few regional studies have investigated the costs of IHD in Iran. However, no comprehensive studies have been conducted on the inpatient costs of IHD and its determinants in Iran. The availability of correct information on the cost of illness can help make the right decisions on therapeutic and preventing plans. Furthermore, understanding the factors affecting the hospitalization costs can aid health policymakers to adopt control measures against the high costs of IHD.

\section{Objectives}

This study aimed to measure the hospitalization expenses of inpatients with IHD and analyze the influencing factors of these costs in Iran.

\section{Methods}

\subsection{Study Design}

This descriptive-analytical cross-sectional retrospective study was conducted in 31 provinces of Iran to evaluate the direct medical costs of inpatients with IHD from health system perspective. The bottom-up approach was used to calculate the costs. The micro-costs for each patient were extracted from the patients' hospital files. The hospitalization bills of all patients with IHD who were supported by Iran Health Insurance Organization were examined from August 23, 2019 to June 20, 2020. Only patients covered by Iran Health Insurance Organization were examined because it covers nearly half of the Iranian community and is known as the second largest insurance organization in Iran; it also provided the researcher a more complete and accurate data set. This organization has five insurance funds including civil servants, rural, Iranian, public health, and other sectors $(20,21)$.

Patients with IHD were identified by ICD-10 (the International Classification of Diseases Tenth Revision) codes of (I24.0, I24.1, I24.8, I24.9, I25.0, I25.1, I25.2, I25.3, I25.4, I25.5, I25.6, I25.8, and I25.9). Then, demographic information and hospitalization costs were gathered from the Health Information System of Iran Health Insurance Organization.

\subsection{Sampling Method and Sample Size}

This study was conducted using complete enumeration method. All the hospitalized IHD patients supported by Iran Health Organization funds were examined at the affiliated hospitals across Iran. The hospitalization files of 68726 patients with IHD were examined, of which 27369 files were excluded due to lacking the necessary criteria. Finally, 41357 files were included in the final analysis.

The excluded files were as follows:

(1) Fast track patients due to not being considered as inpatients

(2) Global records or per-case payment system (PPS) due to the low number (only four files)

(3) Patients with a LOS $\leq$ one day based on the experts' opinions

(4) Patients with 0 or missing hospitalization costs

(5) Patients with missed data of LOS and the newlyestablished hospitals not accredited yet.

\subsubsection{Fast Track Patients}

The fast track consisted of three cubicles and a chair located near the emergency department but separate from the main department. The fast track system was designed for low acuity and ambulatory patients. So, the emphasis was on the rapid turnover, reducing waiting time, and LOS. These patients usually receive cares for less than six hours and are completely recovered and then discharged. Patients who need hospitalization or long-term care were transferred to other parts of emergency departments (22).

\subsubsection{Global Records}

The global payment system is the first example of a percase payment system that covers about 60 common surgeries, for which payments are based on the average cost per case in Iran. We extracted the micro-costs for each patient from the patients' hospital files (23). 


\subsection{Variables and Their Measurement}

The response variable was the sum of various expenses incurred during the hospitalization period, which consisted of visit and consultation, surgical services, drug, and consumable medical supplies, para-clinical services, laboratory tests, medical interventions, rehabilitation, nursing, and hoteling services, and other services. Also, the explanatory variables included demographic information (age, gender, and type of insurance fund), LOS, ICU admission (as a proxy of disease severity), accreditation grade, hospital ownership, and discharge status.

Hospital accreditation is the process of systematically evaluating and determining the credibility of a hospital conducted by an external organization using appropriate structural, procedural, and outcome standards (24). The accreditation degrees of hospitals are determined by their acquired scores. Accordingly, the hospitals are rated as top grade, grade 1 , grade 2 , grade 3 , and non-standard.

The tariffs notified by Iran's Ministry of Health and Medical Education are based on the accreditation grades of hospitals, such that hospitals with higher accreditation grades have higher charges (25).

Regarding hospital ownership, hospitals are classified as private, charity, social security, teaching governmental, and non-teaching governmental in Iran. The cost differences of hospitals depend on the tariffs approved by the government. These tariffs are divided into public and private groups. Private tariffs also include non-governmental public tariffs. Among these five classes, private hospitals use private tariffs, while teaching governmental and nonteaching governmental hospitals use public tariffs (26). Moreover, social security hospitals and charity hospitals benefit from a combination of public and private tariffs for their services (26).

\subsection{Statistical Analysis}

Percentage and frequency were employed to describe the characteristics of patients, whereas mean and standard deviation were utilized to describe hospitalization costs and relative variables. The following multiple linear regression model was adopted to analyze the factors affecting the hospitalization expenses $(27,28)$ :

$\mathrm{Y}=\alpha+\mathrm{B}_{1} \mathrm{X}_{1}+\mathrm{B}_{2} \mathrm{X}_{2}+\ldots \mathrm{B}_{\mathrm{n}} \mathrm{X}_{\mathrm{n}}+\mathrm{v}$

where $\alpha$ indicates a constant and $\mathrm{v}$ shows the random error. Furthermore, $X_{i}$ refers to the ith factor affecting the hospitalization costs, and $\mathrm{B}_{\mathrm{i}}$ is the regression factor of the ith independent variable proving the mean of variations in $y$ when $X_{i}$ increases or decreases by one unit under the assumption that other variables are constant.

Multiple regression analysis is a highly flexible system to examine the relationship between several indepen- dent variables and a single dependent variable. The independent variables may be quantitative or categorical (27, 28 ). Since the presumptions of the multiple linear regression model, ie, normality and consistency variance were not met, the logarithm of the response variable was determined based on ten to fulfill the model assumptions. When these assumptions were fulfilled, the multiple linear regression model was employed to estimate the coefficients of each variable. However, since the coefficients were obtained from logarithm based on ten, they were reversed to their first status. For this purpose, the inverse logarithm was used based on ten. All statistical tests were conducted at the significance level of $\mathrm{P}<0.05$ using the $\mathrm{R}$ 3.6.3 software. The costs were presented in both forms of Iranian Rials (IRR) and USD (2020) (1\$ = 149000 IRR) (29)

\section{Results}

As provided in Table 1, 54.4\% $(\mathrm{n}=22483)$ of cases were male and 55.32\% $(n=22882)$ were single. The mean age of hospitalized patients was 63.95 years ( $S D=12.63)$, and the most prevalent age group was 61 - 70 years $(31.6 \%, n=13081)$. The minimum and maximum hospitalization days were 2 and 160 days, respectively, while the average LOS was 4.92 \pm 5.41 days. The mean ICU LOS was $2.37 \pm 3.93$ days, and $63.5 \%(n=26243)$ of patients had been admitted to the ICU. In term of accreditation grade, most hospitals received top grade and grade $1(\mathrm{n}=39042,94.4 \%)$. Regarding insurance coverage, most people were covered by rural insurance (n $=19253,46.6 \%$ ), and the lowest rate was related to Iranian health insurance $(5.2 \%, \mathrm{n}=2130)$. Regarding the hospital ownership, 97.3\% $(n=40252)$ of hospitals were teaching governmental hospitals, while $0.1 \%(n=22)$ of them were social security hospitals. Moreover, 53.3\% ( $n=22053), 34.1 \%$ $(\mathrm{n}=14113), 7.2 \%(\mathrm{n}=2988), 2.5 \%(\mathrm{n}=1014), 2 \%(\mathrm{n}=816)$, and $0.9 \%(n=373)$ of patients were discharged with relative recovery, complete recovery, discharge against medical advice (DAMA), death, follow-up, and transfer to other medical centers, respectively. According to the findings of the multiple linear regression model in Table 1, hospitalization costs were significantly different in terms of age, gender, type of insurance, LOS, ICU stay, hospital accreditation degree, hospital ownership, and discharge status. The hospitalization costs of men were $24 \%$ higher than those of women. Patients aged 50 and below (23\%), 51 - 60 (37\%), 60 71 (38\%), and 70 - 81 (27\%) had significantly higher hospitalization costs than those aged above 80 years old.

Regarding the accreditation grade, top-grade and firstgrade hospitals had higher hospitalization costs. The Iranian insurance (21\%) and public health insurance had significantly higher hospitalization costs than the civil servants insurance, whereas the hospitalization costs of pa- 
Table 1. Inpatient Characteristics Associated with Inpatient Costs of IHD ( $N=41357)$

\begin{tabular}{|c|c|c|c|c|c|c|}
\hline Variables & No. $(\%)$ & Coefficient & SE & & Main Coefficient & P-Value \\
\hline \multicolumn{7}{|l|}{ Gender } \\
\hline Male & $18874(45.6)$ & 0.0952875 & 0.0032260 & & 1.245 & $<0.001$ \\
\hline Female & $22483(54.4)$ & & & Ref & & \\
\hline \multicolumn{7}{|l|}{ Age } \\
\hline$\leq 50$ & $5677(13.7)$ & 0.0906509 & 0.0066650 & & 1.232 & $<0.001$ \\
\hline $51-60$ & $10377(25.1)$ & 0.1371036 & 0.0059389 & & 1.37 & $<0.001$ \\
\hline $61-70$ & $13081(31.6)$ & 0.1392447 & 0.0057339 & & 1.38 & $<0.001$ \\
\hline $71-80$ & $7960(19.2)$ & 0.1020007 & 0.0061347 & & 1.27 & $<0.001$ \\
\hline$>80$ & $4262(10.3)$ & & & Ref & & \\
\hline \multicolumn{7}{|l|}{ Accreditation grade } \\
\hline Top grade and grade 1 & $39042(94.4)$ & & & Ref & & \\
\hline Grade 2 & $2236(5.4)$ & -0.1763827 & 0.0469649 & & 0.67 & $<0.001$ \\
\hline Grade 3 & $32(0.1)$ & -0.4526562 & 0.0568424 & & 0.35 & $<0.001$ \\
\hline Grade 4 & $47(0.1)$ & -0.1411538 & 0.0070253 & & 0.72 & $<0.001$ \\
\hline \multicolumn{7}{|l|}{ LOS } \\
\hline$\geq 5$ & $28160(68.1)$ & 0.4654241 & 0.0035035 & & 2.92 & $<0.001$ \\
\hline$<5$ & $13197(31.9)$ & & & Ref & & \\
\hline \multicolumn{7}{|l|}{ ICU admission } \\
\hline Yes & $26243(63.5)$ & 0.2095755 & 0.0033662 & & 1.62 & $<0.001$ \\
\hline No & $15114(36.5)$ & & & Ref & & \\
\hline \multicolumn{7}{|l|}{ Insurance fund } \\
\hline Iranian & $2130(5.2)$ & 0.090193 & 0.007845 & & 1.21 & $<0.001$ \\
\hline Rural & $19253(46.6)$ & -0.005515 & 0.004339 & & 0.97 & $<0.01$ \\
\hline Other sectors & $5081(12.3)$ & -0.014190 & 0.005776 & & 0.95 & $<0.001$ \\
\hline Public health & $6686(16.2)$ & 0.017837 & 0.005418 & & 1.03 & $<0.01$ \\
\hline Civil servants & $8207(19.8)$ & & & Ref & & \\
\hline \multicolumn{7}{|l|}{ Hospital ownership } \\
\hline Teaching governmental & $40252(97.3)$ & & & Ref & & \\
\hline Non-teaching governmental & $217(0.5)$ & 0.0155020 & 0.0685513 & & 1.03 & $\mathrm{~ns}$ \\
\hline Social security & $22(0.1)$ & 0.0005965 & 0.0220488 & & 1.001 & ns \\
\hline Charity & $218(0.5)$ & 0.1960379 & 0.0219046 & & 1.57 & $<0.001$ \\
\hline Private & $648(1.6)$ & 0.2820316 & 0.0130724 & & 1.91 & $<0.001$ \\
\hline \multicolumn{7}{|l|}{ Discharge status } \\
\hline Complete recovery & $14113(34.1)$ & -0.2065434 & 0.0106285 & & 0.63 & $<0.001$ \\
\hline Relative recovery & $22053(53.3)$ & -0.2301226 & 0.0105107 & & 0.59 & $<0.001$ \\
\hline Follow-up & $816(2)$ & -0.2868844 & 0.0152341 & & 0.51 & $<0.001$ \\
\hline Transfer to another center & $373(0.9)$ & -0.3527438 & 0.0195632 & & 0.44 & $<0.001$ \\
\hline Discharge against medical advice & $2988(7.2)$ & -0.2046693 & 0.0118100 & & 0.62 & $<0.001$ \\
\hline Death & $1014(2.5)$ & & & Ref & & \\
\hline
\end{tabular}


tients with the insurance of other sectors (5\%) and rural insurance $(3 \%)$ were lower. The hospitalization costs of private hospitals (91\%) and charity hospitals were higher than those of teaching governmental hospitals; however, no significant differences were reported between nongovernmental public hospitals and non-teaching governmental hospitals in terms of hospitalization costs. The patients transferred to other centers (56\%), in need of followup (49\%), gained relative recovery (41\%), and gained complete recovery (27\%) had significantly lower hospitalization costs than the deceased patients.

$\mathrm{R} 2$ and Adjusted $\mathrm{R}$, which have the same values in this study (0.437), mean that the variables in the model were able to predict $43 \%$ of the changes in the response variable. However, our main goal was not to make predictions, but to focus on R2 and Adjusted R.

Table 2 illustrates the mean costs of hospitalization and its components in USD and IRR. The total hospitalization expenses and their average in 2020 were respectively 19.54 million USD and 472.51 USD. Among the components of hospitalization costs, the highest portions were attributed to drugs and consumable medical supplies (29.54\%) and nursing service and hoteling (29.4\%), followed by surgical services (22.53\%), diagnosis services (6.4\%), visit and consultation (5.22\%), laboratory tests (4.08\%), therapeutic interventions (1.46\%), rehabilitation (1.2\%), and other services $(0.18 \%)$. The components of hospitalization costs have also been shown in Figure 1.

\section{Discussion}

The main purpose of this study was to calculate the hospitalization expenditure of inpatients with IHD and analyze the related factors in Iran. The mean and standard deviation of hospitalization costs per patient and per hospitalization day was estimated at $586.42 \pm 472.51$ USD and $103.64 \pm 100.29$ USD, respectively, which were lower than the mean hospitalization costs of IHD patients in Hong Kong (3350 USD) (30) and Brazil (1976 USD) (15). Possible reasons for these differences might be due to the increased prices of medical equipment and services, modern medical technologies, differences in the healthcare models of the two countries, different samples and perspectives, inclusion criteria, calculation of costs, sanctions, and the dramatic fall of Iran's currency. In Iran, governmental hospitals are subsidized by the state; thus, their tariffs are lower than the costs of services. Since the costs were based on the approved tariffs in this study, they were lower than the actual values. In some other studies conducted in the rural areas of China (31), urban areas of China (32), and Shanghai (33), the mean hospitalization costs of patients with chronic heart diseases was reported at 1012.47 USD, 6791.38
USD, and 2546.59 USD, respectively, which were also higher than those presented in our study. This might be due to the fact that these studies estimated the hospitalization costs of patients with chronic heart diseases, including myocardial infarction, angina pectoris, and IHD, but our research considered only patients with IHD. However, the mean hospitalization costs reported by the present study were higher than those suggested by Ribeiro et al. in public sectors in Brazil (34) and Darba et al. in Iran (17). Similar to a study conducted by Ding et al. (32), the highest shares of hospitalization costs were attributed to drugs and consumable medical supplies (140 USD, 29.54\%) and nursing and hoteling services (139 USD, 29.4\%). These high costs can be caused by the excessive use of cardiac stents and expensive cardiac drugs. Furthermore, the high costs of nursing and hoteling services can be explained by the fact that the majority of patients were in ICUs, where the expenses of human resources and bed-per-day are very high.

Our findings revealed a higher hospitalization cost among men than women, which was supported by previous studies $(15,31,32,35)$. Since men have more unhealthy life habits compared to women in Iran (eg, smoking and drinking alcoholic beverages), they have various underlying diseases and more severe CVDs (36). According to the findings, the age groups below 80 were significantly correlated with the increased hospitalization costs, which were much higher in patients aged 51 - 60 and 61 - 70 years old by $37 \%$ and $38 \%$, respectively. Other studies also reported that younger patients had higher hospitalization costs than their older peers $(31,33,37)$; this might be attributed to the fact that old patients selected relatively conservative treatments such as fewer cardiac stents, less aggressive therapies, and more drugs (32). There were also significant differences between the hospital costs in terms of their accreditation grades. The tariffs of hospitals were correlated with their accreditation grades (25, such that top-grade and grade 1 hospitals had higher costs than those of grade 2 , grade 3 , and grade 4 .

The mean LOS for patients with IHD was reported as 4.92 days, which was close to the mean LOS for patients with CHD in China (4 days) (32) and United States (4.9 days) (38). However, some studies claimed longer mean LOS (31, 35). The LOS was significantly associated with the higher hospitalization costs, which was similar to some previous studies $(31,32,39)$. Patients with excess hospitalization days had more critical illnesses, further comorbidity, and higher risk factors. Hence, they needed more resources and services over time and received aggressive measures that were positively related to higher costs (39). Consistent with some studies $(35,37)$, the present study revealed that ICU admission was significantly correlated with the increased hospitalization costs. 


\begin{tabular}{lcccccc}
\hline Table 2. Medical Expenditures for Ischemic Heart Disease Hospitalization (2020 USD Dollars) & & & & \\
\hline Costs & Percent (\%) & Minimum & Maximum & Mean (IRR) & Mean (US \$) & SD \\
\hline Hospitalization per patient & 100 & 17.7262 & $14,287.80$ & 70404136.18 & 472.51 & 586.42 \\
Hospitalization per day & 100 & 8.9 & 1387.07 & 15442757.46 & 103.64 & 100.30 \\
\hline Visit and consultation & 5.22 & 0 & $1,158.11$ & 3675095.91 & 24.7 & 28.16 \\
\hline Surgical services & 22.53 & 0 & $1,710.81$ & 15862051.9 & 106 & 129.66 \\
\hline Drugs and consumable medical supplies & 29.54 & 0 & $3,081.04$ & 20790341.4 & 140 & 163.65 \\
Diagnosis services & 6.4 & 0 & $2,284.84$ & 4505864.72 & 30.2 & 44 \\
\hline Laboratory tests & 4.08 & 0 & 742.92 & 2872488.76 & 19.3 & 26.9 \\
Intervention & 1.46 & 0 & $1,024.8$ & 1027900.4 & 6.9 & 33.78 \\
\hline Rehabilitation & 1.2 & 0 & $1,173.17$ & 844849.63 & 5.67 & 31.51 \\
Nursing and hoteling & 29.4 & 7.0173 & $7,422.94$ & 20698816 & 139 & 174.62 \\
\hline Others & 0.18 & 0 & 434.4 & 126727.44 & 0.85 & 7.37 \\
\hline
\end{tabular}

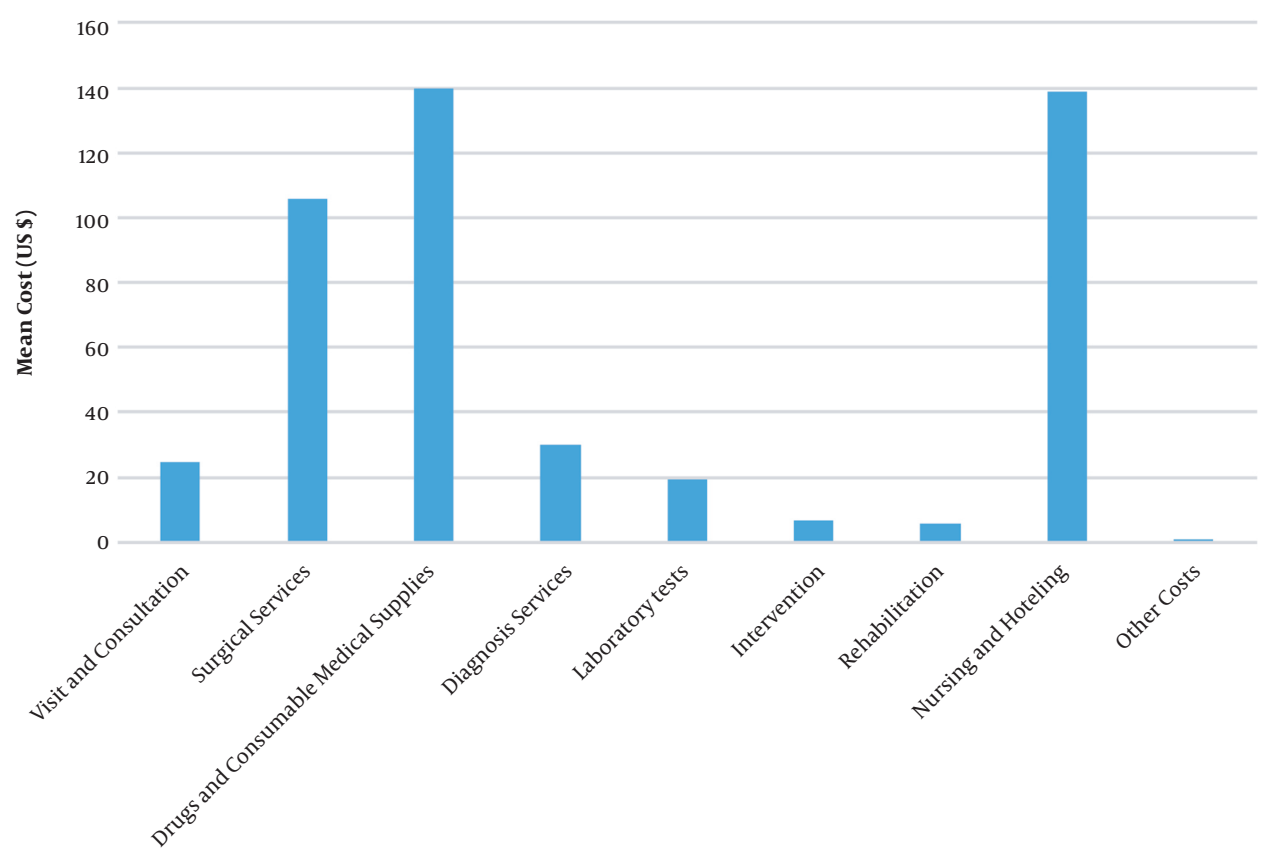

Figure 1. Components of hospitalization costs of ischemic heart disease

ICUs have the latest medical equipment and provide the highest level of medical and nursing care for critically ill patients. Therefore, the costs of hoteling and nursing services are high in ICUs.

Due to numerous serious differences between the structures of Iranian medical insurances and those of other countries, it was impossible to match the results with other countries. Based on the results, the highest mean of hospitalization costs was related to the Iranian and public health insurance funds, while the lowest aver- age costs were seen in the funds of other sectors. Iranian health insurance and public health insurance funds cover the people without any medical insurance. These individuals usually apply for insurance notes only when they need to be hospitalized in the case of severe symptoms of diseases. They require lengthy stays and further diagnostic and therapeutic procedures that increase the average costs of these insurance funds compared to the other funds (40).

In this study, private and charity hospitals reported 91\% and 57\% increases in the mean hospitalization costs, 
respectively, compared to teaching governmental hospitals. A study conducted by Mehraban et al. indicated that the catastrophic costs of healthcare services in private and charity hospitals were higher compared to other hospitals since the hoteling tariffs of private hospitals were 2.6 - 5 times higher than governmental tariffs (26). These findings were also confirmed by some previous studies $(41,42)$. As previously reported $(34,43)$, the mean hospitalization costs in the deceased patients were higher than the recovered ones. The deceased patients were unwell individuals with critical conditions who required a higher level of healthcare services, so in turn, had higher costs of treatment and drugs. In the present study, the patients transferred to other centers to receive healthcare services had the lowest hospitalization costs because the referring hospitals lacked expensive and specialized equipment and facilities for CVDs; therefore, they had lower hospitalization costs than the specialized centers.

A key strength of the present study is that its results can be used as input for health economics models and economic evaluations (such as cost-effectiveness). However, this study had some limitations. First, the statistical sample included only the patients supported by Iran health insurance funds, and it did not involve those supported by social security, armed forces, and private insurances. However, Iran Health Insurance Organization is the second largest insurance organization in Iran with 42 million clients, accounting for $65 \%$ of the entire population of Iran. Second, there were no data regarding household income, employment, education, number of hospitalizations, and comorbidity in the target group; these factors could have a significant effect on hospitalization costs, and the lack of them limited the multiple regression analyses. So, these problems should be solved in future studies. Third, we excluded the global records, which were different from the hospitalization records in terms of cost. It is suggested that future studies focus on the global records of ischemic heart patients and calculate their costs. Fourth, we did not consider overhead costs that may lead to low estimates of actual hospital costs, since overhead costs such as administration, laundry, cleaning, water, electricity, and those related to the LOS generally account for a large portion of total costs.

\subsection{Conclusions}

IHD is one of the most common, serious, and costly CVDs. Therefore, it is necessary to manage the treatment costs of this disease and evaluate its influencing factors. The cost information presented in this study can be used to calculate the economic burden of disease, costeffectiveness of preventive and therapeutic interventions, and to identify strategies on hospital cost management related to this disease. Reducing the costs of IHD through prevention can help save the governmental budget; as a result, the state will be able to spend this portion of GDP improving other national conditions in other sectors. In addition, health policymakers can distribute resources more efficiently and optimally by knowing the costs of IHD.

\section{Acknowledgments}

The authors would like to thank Iran health insurance organization for the information provided.

\section{Footnotes}

Authors' Contribution: Study concept and design: M. SH., S. E., and R. D. Analysis and interpretation of data: M. SH., M.T., S.E., R.D., and H.K. Drafting of the manuscript: M. SH., S. E., Z. K., and H.K. Statistical analysis: M. SH., M. T., H. K., Z. K., and R. D.

Conflict of Interests: The authors declared no conflict of interest.

Ethical Approval: This research was part of a $\mathrm{PhD}$ thesis approved by the Ethics Committee of Tehran University of Medical Sciences (code: IR.TUMS.SPH.REC.1397.288).

Funding/Support: This research was funded by the Vice Chancellor for Research at Tehran University of Medical Sciences, Iran.

\section{References}

1. Sarrafzadegan N, Mohammmadifard N. Cardiovascular Disease in Iran in the Last 40 Years: Prevalence, Mortality, Morbidity, Challenges and Strategies for Cardiovascular Prevention. Arch Iran Med. 2019;22(4):204-10. [PubMed: 31126179].

2. Roth GA, Johnson C, Abajobir A, Abd-Allah F, Abera SF, Abyu G, et al. Global, Regional, and National Burden of Cardiovascular Diseases for 10 Causes, 1990 to 2015. J Am Coll Cardiol. 2017;70(1):1-25. doi: 10.1016/j.jacc.2017.04.052. [PubMed: 28527533]. [PubMed Central: PMC5491406].

3. Yazdanyar A, Newman AB. The burden of cardiovascular disease in the elderly: morbidity, mortality, and costs. Clin Geriatr Med. 2009;25(4):563-77. doi: 10.1016/j.cger.2009.07.007. [PubMed: 19944261]. [PubMed Central: PMC2797320].

4. Rezende PC, Ribas FF, Serrano CJ, Hueb W. Clinical significance of chronic myocardial ischemia in coronary artery disease patients. $J$ Thorac Dis. 2019;11(3):1005-15. doi: 10.21037/jtd.2019.02.85. [PubMed: 31019790]. [PubMed Central: PMC6462715].

5. Dai H, Much AA, Maor E, Asher E, Younis A, Xu Y, et al. Global, regional, and national burden of ischaemic heart disease and its attributable risk factors, 1990-2017: results from the Global Burden of Disease Study 2017. Eur Heart J Qual Care Clin Outcomes. 2020;8(1):5060. doi: 10.1093/ehjqcco/qcaa076. [PubMed: 33017008]. [PubMed Central: PMC8728029].

6. World Health Organization. Global status report on non-communicable diseases. Geneva, Switzerland: World Health Organization; 2011. 
7. Gaziano TA, Bitton A, Anand S, Abrahams-Gessel S, Murphy A. Growing epidemic of coronary heart disease in low- and middle-income countries. Curr Probl Cardiol. 2010;35(2):72-115. doi: 10.1016/j.cpcardiol.2009.10.002. [PubMed: 20109979]. [PubMed Central: PMC2864143].

8. Viz Hub. Global burden of disease. Viz Hub; 2021. Available from: https: //vizhub.healthdata.org/gbd-compare.

9. Raghfar H, Sargazi N, Mehraban S, Akbarzadeh MA, Vaez Mahdavi MR, Vahdati Manesh Z. The Economic Burden of Coronary Heart Disease in Iran: A Bottom-up Approach in 2014. J Ardabil Univ Med Sci. 2018;18(3):341-56. doi:10.29252/jarums.18.3.341.

10. Luengo-Fernandez R, Leal J, Gray A, Petersen S, Rayner M. Cost of cardiovascular diseases in the United Kingdom. Heart. 2006;92(10):13849. doi: 10.1136/hrt.2005.072173. [PubMed: 16702172]. [PubMed Central: PMC1861058].

11. Muka T, Imo D, Jaspers L, Colpani V, Chaker L, van der Lee SJ, et al. The global impact of non-communicable diseases on healthcare spending and national income: a systematic review. Eur J Epidemiol. 2015;30(4):251-77. doi: 10.1007/s10654-014-9984-2. [PubMed: 25595318].

12. Santos JV, Vandenberghe D, Lobo M, Freitas A. Cost of cardiovascular disease prevention: towards economic evaluations in prevention programs. Ann Transl Med.2020;8(7):512. doi:10.21037/atm.2020.01.20. [PubMed: 32395556]. [PubMed Central: PMC7210201].

13. Tarride J, Lim M, DesMeules M, Luo W, Burke N, O'Reilly D, et al. A review of the cost of cardiovascular disease. Can J Cardiol. 2009;25(6):195-202. doi: 10.1016/s0828-282x(09)70098-4.

14. Vandenberghe D, Albrecht J. The financial burden of noncommunicable diseases in the European Union: a systematic review. Eur J Public Health. 2020;30(4):833-9. doi: 10.1093/eurpub/ckz073. [PubMed: 31220862].

15. Schlatter RP, Hirakata VN, Polanczyk CA. Estimating the direct costs of ischemic heart disease: evidence from a teaching hospital in BRAZIL, a retrospective cohort study. BMC Cardiovasc Disord. 2017;17(1):180. doi: 10.1186/s12872-017-0615-1. [PubMed: 28676042]. [PubMed Central: PMC5496598].

16. Caruba T, Chevreul K, Zarca K, Cadier B, Juilliere Y, Dubourg O, et al. Annual cost of stable coronary artery disease in France: A modeling study. Arch Cardiovasc Dis. 2015;108(11):576-88. doi: 10.1016/j.acvd.2015.06.006. [PubMed: 26433733].

17. Darba S, Safaei N, Mahboub-Ahari A, Nosratnejad S, Alizadeh G, Ameri $\mathrm{H}$, et al. Direct and Indirect Costs Associated with Coronary Artery (Heart) Disease in Tabriz, Iran. Risk Manag Healthc Policy. 2020;13:96978. doi: 10.2147/RMHP.S261612. [PubMed: 32801971]. [PubMed Central: PMC7406327].

18. Chang HS, Kim HJ, Nam CM, Lim SJ, Jang YH, Kim S, et al. The socioeconomic burden of coronary heart disease in Korea. J Prev Med Public Health. 2012;45(5):291-300. doi: 10.3961/jpmph.2012.45.5.291. [PubMed: 23091654]. [PubMed Central: PMC3469811].

19. Thom T, Haase N, Rosamond W, Howard VJ, Rumsfeld J, Manolio T, et al. Heart disease and stroke statistics-2006 update: a report from the American Heart Association Statistics Committee and Stroke Statistics Subcommittee. Circulation. 2006;113(6):e85-151. doi: 10.1161/CIRCULATIONAHA.105.171600. [PubMed: 16407573].

20. Doshmangir L, Bazyar M, Rashidian A, Gordeev VS. Iran health insurance system in transition: equity concerns and steps to achieve universal health coverage. Int J Equity Health. 2021;20(1):37. doi: 10.1186/s12939-020-01372-4. [PubMed: 33446202]. [PubMed Central: PMC7807408].

21. Iran Health Insurance Organization. Insurance coverage \& Funds. Iran Health Insurance Organization; 2020. Available from: https://en.ihio. gov.ir/Funds.

22. O'Brien D, Williams A, Blondell K, Jelinek GA. Impact of streaming "fast track" emergency department patients. Aust Health Rev. 2006;30(4):525-32. doi: 10.1071/ah060525. [PubMed: 17073548].

23. Goudari FB, Rashidian A, Arab M, Mahmoudi M, Jaafaripooyan E. A trend analysis of surgical operations under a global payment system in Tehran, Iran (2005-2015). Electron Physician. 2018;10(3):6506-15. doi 10.19082/6506. [PubMed: 29765576]. [PubMed Central: PMC5942572].

24. Mosadeghrad AM, Akbari Sari A, Yousefinezhadi T. [Evaluation of hospital accreditation method]. Tehran Univ Med J. 2017;75(4):288-98. Persian.

25. Yousefinezhadi T, Mosadeghrad AM, Arab M, Ramezani M, Sari AA. An Analysis of Hospital Accreditation Policy in Iran. Iran J Public Health. 2017;46(10):1347-58. [PubMed: 29308378]. [PubMed Central: PMC5750346].

26. Mehraban S, Raghfar H. The Place of Health Insurance in Reducing Catastrophic Health Expenditure. Iran J Econ Stud. 2018;7(2):239-54.

27. Agresti A. Categorical Data Analysis. 2nd ed. New Jersey, USA:John Wiley \& Sons; 2002. p.166-82. doi:10.1002/0471249688.

28. Uyanık GK, Güler N. A Study on Multiple Linear Regression Analysis. Procedia Soc Behav Sci. 2013;106:234-40. doi: 10.1016/j.sbspro.2013.12.027.

29. Central Bank of the Islamic Republic of Iran. [Weighted average exchange rate]. Central Bank of the Islamic Republic of Iran; 2021. Persian. Available from: https://fxmarketrate.cbi.ir.

30. Lee VW, Lam YY, Yuen AC, Cheung SY, Yu CM, Yan BP. Direct medical cost of newly diagnosed stable coronary artery disease in Hong Kong. Heart Asia. 2013;5(1):1-6. doi: 10.1136/heartasia-2012-010168. [PubMed: 27326062]. [PubMed Central: PMC4832635].

31. Wang Q, Zhang S, Wang Y, Zhang X, Zhang Y. Factors Associated With Hospitalization Costs of Coronary Heart Disease in Township Hospitals in Rural China. Inquiry. 2019;56:46958019886958. doi: 10.1177/0046958019886958. [PubMed: 31701787]. [PubMed Central: PMC6843734].

32. Ding JM, Zhang XZ, Hu XJ, Chen HL, Yu M. Analysis of hospitalization expenditures and influencing factors for inpatients with coronary heart disease in a tier-3 hospital in Xi'an, China: A retrospective study. Medicine (Baltimore). 2017;96(51). e9341. doi: 10.1097/MD.0000000000009341. [PubMed: 29390516]. [PubMed Central: PMC5758218].

33. Wang S, Petzold M, Cao J, Zhang Y, Wang W. Direct medical costs of hospitalizations for cardiovascular diseases in Shanghai, China: trends and projections. Medicine (Baltimore). 2015;94(20). e837. doi: 10.1097/MD.0000000000000837. [PubMed: 25997060]. [PubMed Central: PMC4602857].

34. Ribeiro RA, Mello RG, Melchior R, Dill JC, Hohmann CB, Lucchese AM, et al. [Annual cost of ischemic heart disease in Brazil. Public and private perspective].Arq Bras Cardiol. 2005;85(1). portuguese. doi: 10.1590/s0066-782x2005001400002.

35. Sozmen K, Pekel O, Yilmaz TS, Sahan C, Ceylan A, Guler E, et al. Determinants of inpatient costs of angina pectoris, myocardial infarction, and heart failure in a university hospital setting in Turkey. Anatol J Cardiol. 2015;15(4):325-33. doi: 10.5152/akd.2014.5320. [PubMed: 25413230]. [PubMed Central: PMC5336844].

36. Zhou M, Wang H, Zhu J, Chen W, Wang L, Liu S, et al. Cause-specific mortality for 240 causes in China during 1990-2013: a systematic subnational analysis for the Global Burden of Disease Study 2013. Lancet. 2016;387(10015):251-72. doi:10.1016/s0140-6736(15)00551-6.

37. Zhang H, Yin Y, Zhang C, Zhang D. Costs of hospitalization for stroke from two urban health insurance claims data in Guangzhou City, southern China. BMC Health Serv Res. 2019;19(1):671. doi: 10.1186/s12913019-4530-2. [PubMed: 31533714]. [PubMed Central: PMC6749676].

38. Etemad LR, McCollam PL. Total first-year costs of acute coronary syndrome in a managed care setting.JManag Care Pharm. 2005;11(4):3006. doi: 10.18553/jmcp.2005.11.4.300. [PubMed: 15871640].

39. Jan S, Lee SW, Sawhney JPS, Ong TK, Chin CT, Kim HS, et al. Predictors of high-cost hospitalization in the treatment of acute coronary syndrome in Asia: findings from EPICOR Asia. BMC Cardiovasc Disord. 2018;18(1):139. doi: 10.1186/s12872-018-0859-4. [PubMed: 29973147]. [PubMed Central: PMC6033225]. 
40. Hajinabi K, Selseleh M. The relation between insurance funds of medical service insurance and heart inpatients costs in Karaj hospitals (Iran).J Res Health. 2012;2(2):207-13.

41. Doshmangir L, Rashidian A, Kouhi F, Gordeev VS. Setting health care services tariffs in Iran: half a century quest for a window of opportunity. Int J Equity Health. 2020;19(1):112. doi: 10.1186/s12939-020-01224-1. [PubMed: 32631344]. [PubMed Central: PMC7336437].

42. Soysal A, Yağar F. Evaluation of Quality and Cost in Public and Pri- vate Health Care Institutions: A Case Study in Turkey. Int J Bus Soc Sci. 2017;8(2).

43. Yoon SS, Chang H, Kwon YD. Itemized hospital charges for acute cerebral infarction patients influenced by severity in an academic medical center in Korea. J Clin Neurol. 2012;8(1):58-64. doi: 10.3988/jcn.2012.8.1.58. [PubMed: 22523514]. [PubMed Central: PMC3325433]. 